\title{
Usos Lícito e llícito dos Fármacos
}

\author{
Licit and Ilicit Uses of Medicines
}

\author{
Ricardo Jorge DINIS-OLIVEIRA ${ }^{1,2,3}$ \\ Acta Med Port 2014 Nov-Dec;27(6):755-766
}

RESUMO

As drogas de abuso são um grupo heterogéneo de xenobióticos ou endobióticos que alteram a organização sináptica no sistema nervoso central, de modo transitório ou permanente, conduzindo frequentemente ao consumo da droga de forma compulsiva. O que une os seus membros é o facto de conferirem prazer (hedonismo) a quem consome, nomeadamente por influência no sistema mesolímbico da dopamina. Para exercerem os seus efeitos, as diferentes drogas de abuso vão atuar sobre recetores e transportadores de neurotransmissores, modelando a libertação destes para a fenda sináptica. Além de atuar em neurónios pré-sinápticos, também atuam nos recetores de neurotransmissores e canais iónicos nos neurónios pós-sinápticos, ocorrendo desta forma, uma modificação das vias de sinalização. Nesta revisão é discutido a farmacodinâmica de algumas substâncias psicoativas que são alvo de consumo abusivo em Portugal. Com esta abordagem é também possível uma discussão das drogas de abuso que exibem efeitos toxicológicos tão diversos como estimulantes, depressores e alucinogénios. Nomeadamente é discutido o potencial dos (i.e. depressores do sistema nervoso central, estimulantes, antiparkinsónicos anticolinérgicos, opioides, alucinogénios e dos canabinoides) para desenvolverem adição e dependência, bem como serem alvo de utilizações lícitas e ilícitas.

Palavras-chave: Antiparkinsonianos; Depressores do Sistema Nervoso Central; Opioides; Antagonistas Colinérgicos; Analgésicos Opioides; Alucinogénios; Estimulantes do Sistema Nervoso Central.

\section{ABSTRACT}

Drugs of abuse are a heterogeneous group of xenobiotics or endobiotics that alter synaptic organization in the central nervous system in a transient or permanent basis, often leading to a compulsively use. What unites its members is that they confer pleasure (hedonism) to the abusers, namely by their action in the mesolimbic dopamine system. To exert its effects, different drugs of abuse will act on receptors and neurotransmitter transporters, modeling neurotransmitter release into the synaptic cleft. Besides acting on presynaptic neurons also function in neurotransmitter receptors and ion channels in postsynaptic neurons, thereby modifying the signaling pathways. In this work, the pharmacodynamic and the potential of some psychoactive substances that are typically subjected to abuse in Portugal, is reviewed. With this approach it was also possible a discussion of drugs of abuse that exhibit very different toxicological effects such as stimulants, depressants and hallucinogens. Particularly, the potential to induce dependence and addition, as well as to undergo illicit and licit uses, of central nervous system depressants, stimulants, anticholinergic antiparkinson drugs, opioids, cannabinoids and hallucinogens, is discussed.

Keywords: Antiparkinson Agents; Central Nervous System Depressants; Cholinergic Antagonists; Analgesics, Opioid; Hallucinogens; Central Nervous System Stimulants.

\section{INTRODUÇÃO}

$\mathrm{O}$ abuso de drogas e medicamentos continua a ser um importante problema de saúde. O United Nations Office on Drugs and Crime (UNODC) reportou em 2010 que cerca de $5 \%$ da população mundial abusava de uma droga ilícita e 27 milhões de pessoas $(\sim 0,6 \%$ da população adulta mundial) podem ser classificados como consumidores problemáticos de drogas de abuso. ${ }^{1}$ Estima-se que os resultados do abuso de álcool em 2,5 milhões de mortes por ano e que a heroína, cocaína e outras drogas são responsáveis por 0,1 a 0,2 milhões de mortes por ano. Além de causar a morte, o abuso de drogas é também responsável por significativa morbidade e o tratamento da dependência de drogas acarreta um enorme peso para a sociedade. O UNODC estima que os custos de todo o mundo relacionados com o tratamento dos toxicodependentes de US $\$ 200$ - $\$ 250$ biliões de dólares ( 0,3-0,4\% do PIB mundial). Além disso, estima-se que apenas $20 \%$ dos toxicodependentes em 2010 foram efetivamente tratados para a sua dependência. ${ }^{2}$

Os estudos existentes encontraram uma elevada correlação entre o abuso de drogas na adolescência e a probabilidade de se tornar um toxicodependente em adulto. ${ }^{3} \mathrm{Na}$ verdade muitos toxicodependentes começam a abusar de drogas em uma idade muito precoce, implicando um alto risco de insucesso escolar, delinquência, gravidez na adolescência e depressão. ${ }^{3}$ Além disso, as mortes acidentais e intencionais que estão associadas com o uso de drogas representam uma das principais causas evitáveis de morte entre os 15 a 24 anos de idade.

Os psicotrópicos ou substâncias psicoativas são compostos (sejam eles xenobióticos ou endobióticos) que atuam primeiramente no Sistema Nervoso Central (SNC), alterando temporariamente a perceção, humor, estado de

1. Departamento de Medicina Legal e Ciências Forenses. Faculdade de Medicina. Universidade do Porto. Porto. Portugal.

2. IINFACTS, Instituto de Investigação e Formação Avançada em Ciências e Tecnológica. Departamento de Ciências. Instituto Superior de Ciências da Saúde Norte. Cooperativa de Ensino Superior Politécnico e Universitário, CRL. Gandra. Portugal.

3. UCIBIO-REQUIMTE. Laboratório de Toxicologia. Departamento de Ciências Biológicas. Faculdade de Farmácia. Universidade do Porto. Porto. Portugal. Recebido: 27 de Janeiro de 2014 - Aceite: 02 de Junho de 2014 | Copyright $\odot$ Ordem dos Médicos 2014 
consciência e o comportamento. Podem de acordo com o estado sócio-legal exibir uso lícito (psicofármacos; que podem também estar sujeitos a abuso) e ilícito (drogas de abuso). As drogas de abuso representam um grupo heterogéneo de compostos com mecanismos de ação muito diversos. ${ }^{4}$ Recentes pesquisas neurobiológicas conduziram à separação conceitual e mecanística da 'dependência' e 'adição'. A velha expressão 'dependência física' é agora referida como 'dependência', enquanto a 'dependência psicológica' é simplesmente designada de adição. A adição (deriva do Latim da palavra addicere que significa "ligar-se a coisas") é a sensação que impele ou motiva de forma compulsiva à obtenção e ao consumo da 'droga' para manter determinado nível de atividade, euforia ou de bem-estar, mesmo em face das consequências negativas. Com o passar do tempo o consumo torna-se compulsivo. É considerada uma doença neuropsiquiátrica que pode existir sem que se verifique dependência e ocorre mais facilmente com xenobióticos que produzem intenso prazer (euforia, felicidade), ou seja recompensa. ${ }^{5}$ Apenas uma percentagem dos consumidores desenvolvem adição, o que é facilmente demonstrado no decurso da terapêutica analgésica com opioides.

A 'dependência' corresponde à adaptação fisiológica ao consumo habitual da 'droga'. Está relacionada com fenómenos de tolerância (resposta adaptativa; o contrário de sensibilização) e síndrome de abstinência (resultante da paragem abrupta no consumo, originando efeitos opostos aos originalmente causados pela droga). ${ }^{6}$ Estes efeitos ocorrem invariavelmente com o consumo crónico (mesmo que para fins terapêuticos) e apenas no indivíduo dependente (seja ele ou não adicto). ${ }^{7}$ Trata-se com programas terapêuticos de redução gradual das doses da droga.

Uma combinação de estudos pré-clínicos e clínicos revelou que o sistema mesolímbico dopaminérgico é o principal alvo das drogas de abuso. Este sistema tem origem na área tegmental ventral (VTA), uma pequena estrutura no tronco cerebral (mesencéfalo), que se projeta para o núcleo accumbens, a amígdala, o hipocampo e o córtex pré-frontal. ${ }^{4}$ A maioria dos neurónios de projeção da VTA são neurónios produtores de dopamina (DA) e quando despolarizam, grandes quantidades de DA são libertadas. Como regra geral, todas as drogas aditivas ativam o sistema mesolímbico da DA.

A literatura é vasta em matéria de drogas de abuso e pouco harmonizada. Várias são as classificações possíveis para as drogas de abuso. Os livros da especialidade, organizam capítulos para as drogas de abuso, tendo em conta a utilidade clínica e os seus efeitos mais importantes ao nível do $\mathrm{SNC}^{7}$ :

a) Opioides - são utilizados sobretudo como analgésicos, antitússicos e antidiarreicos. Este grupo inclui a morfina e outros alcaloides do ópio (codeína), derivados semissintéticos (hidromorfona), bem como substâncias sintéticas semelhantes à morfina e compostos endógenos. Outros exemplos importantes incluem fármacos como o dextrometorfano, metadona, buprenorfina, fentanilo, tramadol, etc.;

b) Alucinogénios como a fenciclidina (PCP) cetamina, dietilamida do ácido lisérgico (LSD), mescalina, psilocibina, psilocina, 3,4-metilenodioximetanfetamina (MDMA, 'ecstasy'), etc.;

c) Depressores do SNC como o etanol, $\mathrm{y}$-hidroxibutírico, benzodiazepinas, barbitúricos, etc.;

d) Estimulantes do SNC como a cocaína, anfetaminas ( $d$-anfetamina, metanfetamina, metilfenidato, MDMA, etc.), cafeína, nicotina, efedrina, etc.;

e) Derivados da Cannabis como a marijuana, haxixe, etc. O xenobiótico presente em todos estes é o delta-9-tetrahidrocanabinol $\left(\Delta^{9}-\mathrm{THC}\right)$;

f) Inalantes (voláteis inalados acidentalmente ou intencionalmente) como o butano, hexano, propano, tolueno, benzeno, gasolina, acetona, óxido nitroso, etc.

De todas as possíveis classificações, talvez a mais científica é aquela que tem por base o mecanismo de ação das drogas de abuso. Uma vez que cada uma tem distintos mecanismos celulares para ativar o sistema mesolímbico, três classes podem ser distinguidas: ${ }^{4}$

a) Classe I (e.g. opioides, canabinoides, mescalina, etc.) - ligam-se a recetores acoplados a proteínas (e.g. $G_{i o}$ e $\mathrm{G}_{\mathrm{q}}$ ) conduzindo à inibição de neurónios por hiperpolarização pós-sináptica e regulação pré-sináptica da liberação de neurotransmissores. Na VTA, a ação desses xenobióticos é, preferencialmente, sobre os neurónios produtores de ácido $\gamma$-aminobutírico (GABA) que funcionam localmente como interneurónios inibitórios. Estes ao serem inibidos promovem a desinibição dos neurónios dopaminérgicos da VTA;

b) Classe II (e.g. benzodiazepinas, cetamina, etanol, etc.) - engloba drogas de abuso que se ligam a recetores ionotrópicos e canais iónicos, podendo ter efeitos combinados sobre os neurónios dopaminérgicos e GABAérgicos, conduzindo a uma maior liberação de DA;

c) Classe III (e.g. cocaína, anfetaminas, etc.) - bloqueiam os transportadores de recaptação e/ou estimulam a liberação não vesicular de DA, noradrenalina (NA), serotonina (5-HT), resultando na acumulação extracelular destes neurotransmissores nas estruturas alvo.

Algumas drogas de abuso, como os alucinogénios, não causam adição; alteram a perceção, sem causar sensações de recompensa e de euforia. Ao contrário das drogas aditivas, que têm como principal alvo o sistema mesolímbico dopaminérgico, os alucinogénios atuam nos circuitos corticais e talâmicos. ${ }^{4}$ A LSD, por exemplo, ativa o recetor $5-\mathrm{HT}_{2 \mathrm{~A}}$ no córtex pré-frontal, facilitando a transmissão glutamatérgica para neurónios piramidais. A PCP e a cetamina produzem uma sensação de separação do corpo da mente (sendo por isso designados de anestésicos dissociativos) e, em doses mais altas, letargia e coma. O principal mecanismo de ação é a inibição dependente da utilização de recetores do glutamato do tipo $\mathrm{N}$-metil-D-aspartato.

Nesta revisão discute-se a farmacodinâmica de algu- 
mas substâncias lícitas e ilícitas que são alvo de consumo abusivo em Portugal. Com esta abordagem é também possível uma discussão das drogas de abuso que exibem efeitos toxicológicos tão diversos como estimulantes, depressores e alucinogénios. A pesquisa bibliográfica foi efetuada na MEDLINE.

\section{DEPRESSORES DO SISTEMA NERVOSO CENTRAL}

Neste tópico será dada particular importância a alguns psicofármacos, nomeadamente à utilização ilícita de ansiolíticos, sedativos e hipnóticos tais como as benzodiazepinas, barbitúricos e hipnóticos não benzodiazepínicos como o zolpidem.

As benzodiazepinas, barbitúricos e o zolpidem ligam-se ao recetor $\mathrm{GABA}_{\mathrm{A}}$ (reduzida afinidade para o recetor $G_{B B A}$ ) das membranas neuronais no SNC. Este recetor funciona como um canal de cloro, o qual é aberto (ativado) pelo neurotransmissor inibitório ácido $\mathrm{y}$-amino butírico (GABA), criando-se uma corrente inibitória. Os depressores do SNC funcionam como moduladores alostéricos (potenciam) da ação do próprio GABA (ou seja não funcionam na ausência deste), promovendo a hiperpolarização das células onde atuam, por favorecer a abertura do canal de cloro. As benzodiazepinas e o zolpidem aumentam a frequência de abertura do canal ao passo que os barbitúricos iniciam e aumentam a duração da abertura. ${ }^{4}$

$\mathrm{Na}$ terapêutica as benzodiazepinas substituíram claramente os barbitúricos, já que são fármacos mais seguros, apresentarem menos efeitos de indução enzimática, logo interações menos graves, sintomas de abstinência menos severos e margem terapêutica alargada. ${ }^{7}$ As benzodiazepinas distinguem-se entre ansiolíticas e hipnóticas. Esta distinção é de alguma forma artificial na medida em que todas são ansiolíticas e que todas podem modificar o sono desde que se atinjam determinadas doses. $O$ que as distingue, contudo, é que as benzodiazepinas ditas hipnóticas são fármacos potentes que podem por isso modificar as condições do sono em doses relativamente baixas, enquanto as benzodiazepinas ditas ansiolíticas são menos potentes, o que permite a existência de uma 'janela terapêutica' em que é possível obter uma ação ansiolítica sem interferir significativamente com o sono. Várias outras utilizações terapêuticas estão descritas, mas fora do âmbito desta revisão. $^{7}$

Os efeitos tóxicos das benzodiazepinas estão na sua maioria relacionados com os efeitos depressores do SNC e destaca-se a sonolência, descoordenação motora e raciocínio diminuído. Têm um impacto significativo na condução de veículos motorizados, capacidade de trabalho e relações interpessoais, pelo que o seu uso deve ser acautelado nestas circunstâncias. ${ }^{8}$ Alteração da memória a curto prazo (capacidade diminuída para aprender nova informação, deixando a já aprendida intacta) - pode ser útil em procedimentos clínicos desconfortáveis (endoscopia) pois o doente coopera durante o procedimento mas fica amnésico relativamente a este. $\mathrm{O}$ uso persistente e mais prolongado do que o recomendado e a automedicação é uma rea- lidade. Todas as benzodiazepinas podem induzir tolerância, dependência e adição, mas em menor grau que os barbitúricos. ${ }^{7}$ As benzodiazepinas de curta duração de ação são as que têm maior potencial de induzir dependência e a síndrome de abstinência pode mesmo ocorrer quando o descontinuar é abrupto. A tolerância para os efeitos hipnóticos das benzodiazepinas desenvolve-se rapidamente, pelo que os tratamentos que têm como objetivo o tratamento da insónia devem ser de curta duração. ${ }^{9}$ As benzodiazepinas sofrem um extenso metabolismo hepático e salienta-se o facto de muitos metabolitos serem ativos afetando a duração dos efeitos e como tal devem ser tidos em conta na interpretação dos resultados clínicos e forenses.

O flunitrazepam (Rohypnol ${ }^{\circledR}$ ) é a benzodiazepina mais implicada no uso ílicito nomeadamente na concretização de agressões sexuais facilitadas por drogas. ${ }^{10}$ Por este motivo é conhecida como pertencente ao grupo das 'drogas da violação', 'drogas predadoras' ou 'drogas recreativas', sendo substancial a sua 'popularidade' em clubes de dança, discotecas e bares. ${ }^{11}$ Nos últimos anos, as agressões sexuais facilitadas por drogas tornaram-se uma preocupação crescente entre os profissionais de saúde e estão ou sinalizados mais de 50 xenobióticos ou endobióticos como suspeitos de terem sido utilizados em casos de ASFD. ${ }^{12} \mathrm{~A}$ verdadeira incidência desta problemática não é conhecida, pois nem todas as vítimas são avaliadas do ponto de vista clínico e/ou forense, nem sujeitas a colheita de amostras para rastreio toxicológico num curto período de tempo após o evento. ${ }^{13} \mathrm{O}$ flunitrazepam é similar ao diazepam, mas cerca de 10 vezes mais potente. Os efeitos sedativos começam ao fim de 30 minutos e tem efeito máximo ao final de duas horas e podem manter-se por mais de 6-8 horas após ingestão. Deixa a pessoa incapaz de resistir, não respondedora, provoca amnésia anterógrada (que pode durar oito horas) dificultando a investigação por falta de dados providos pela vítima. Enquanto a maior parte dos utilizadores adormece no período de duas horas após o consumo, outros permanecem acordados, embora percam o controlo do seu comportamento. É tipicamente administrado per os, dissolvido em água, etanol (risco de interações sinérgicas) ou outros líquidos ou inalado. Pelo facto de não apresentar cor, cheiro, sabor, a Roche ${ }^{\circledR}$ passou a incluir um corante nos comprimidos corando bebidas claras de um tom azulado, uma cerveja de verde e conferem um tom 'nebulado' a bebidas escuras. ${ }^{14} \mathrm{O}$ revestimento origina uma dissolução lenta do comprimido, o que facilita a sua deteção.

Dentro ainda dos depressores é importante alertar para o uso ilícito do endobiótico $\mathrm{y}$-hidroxibutírico (GHB; neurotransmissor central inibitório sintetizado a partir do glutamato), sendo este a verdadeira droga da violação. ${ }^{15} \mathrm{O} \mathrm{GHB}$ agonista do recetor $\mathrm{GABA}_{B}$ onde atua quer diretamente quer indiretamente por metabolização a GABA. ${ }^{16} \mathrm{Na}$ farmacologia é disponibilizado como oxibato de sódio (sal sódico do $\mathrm{GHB}$ ) para o tratamento de vários distúrbios do sono como narcolepsia. ${ }^{17}$ Tanto as intoxicações com GHB como o flunitrazepam podem ser fatais quando misturadas com o etanol, apesar de isoladamente o flunitrazepam ser menos 
propenso que o GHB a fatalidades.

Os barbitúricos são utilizados sobretudo como anti-convulsivantes (os de longa duração de ação), hipnóticos, anestésicos gerais (os de curta duração de ação), ansiolíticos, sedativos e hipnóticos. Destacam-se o tiopental, fenobarbital e pentobrabital de maior representatividade em Portugal. Tal como anteriormente referido, o risco de depressão grave do SNC (inclusive coma e morte) e a existência de alternativas mais seguras (benzodiazepinas) faz com que a sua utilização seja diminuta e reservada a casos especiais (e.g. insónia refratária). ${ }^{9} \mathrm{~A}$ sua utilização ilícita em agressões sexuais facilitadas por drogas é reduzida.

\section{ESTIMULANTES}

Os xenobióticos pertencentes a este grupo exibem em geral um efeito estimulante pronunciado no SNC. Reduzem a sensação de fadiga mental (aumento o estado de alerta) e física (aumento a atividade motora), podem exacerbar a esquizofrenia e causar adição e dependência. ${ }^{18} \mathrm{O}$ uso ininterrupto dos estimulantes por 24-72 horas é referido como run e usualmente termina em crash (24-36 horas a dormir) quando o indivíduo está exausto fisicamente ${ }^{18}$ Administrações IV de cocaína e anfetaminas produzem uma intensa sensação de rush que se assemelham a um orgasmo sexual e quanto mais rápidos os seus efeitos, maior é a recompensa. Estes compostos aumentam as capacidades cognitivas e o humor em baixas doses e com o escalonar da dose durante o run surge o comportamento estereotipado (repetidos) como o bruxismo. ${ }^{19}$ Ativam também o Sistema Nervoso Autónomo (SNA; são sobretudo simpaticomiméticas) resultando em taquicardia, hipertensão, arritmias, hipertermia, midríase, enfarte agudo do miocárdio, anorexia, hemorragia cerebral, convulsões e morte. ${ }^{20}$

\section{Anfetaminas}

Os protótipos dos estimulantes do SNC são as anfetaminas. A cafeína é também um estimulante do SNC mas não está autorizada como especialidade farmacêutica enquanto princípio isolado. No entanto, faz parte, de algumas associações fixas dirigidas ao tratamento da dor ou da sintomatologia das síndromes gripais, cuja utilização é desaconselhada por especialistas. ${ }^{9}$ De facto, a dose de cafeína necessária para potenciar o efeito analgésico nunca é atingida nessas associações, mas a presença da cafeína pode desencadear reações adversas, nomeadamente ansiedade, palpitações e insónia.

O termo 'anfetamina' refere-se ao grupo dos estimulantes, que inclui por exemplo a própria anfetamina, a metanfetamina, a metilenodioxianfetamina e a 3,4-metilenodioximetanfetamina. Estas drogas de abuso de abuso de baixo peso molecular são aminas (logo exibem características básicas) simpaticomiméticas derivadas da feniletilamina e possuem atividade estimulante central e periférica que pode motivar comportamentos aditivos. ${ }^{18}$ As anfetaminas produzem intensa estimulação do SNC mediada pelo aumento da concentração sináptica de NA, 5-HT e DA, seja estimulando a libertação de não vesicular dos neurotrans- missores ou inibindo a recaptação, ou ambos., ${ }^{4,20}$ São por isso designadas de adrenomiméticos de ação indireta uma vez que não ativam diretamente os adrenorecetores. A inibição da recaptação é conseguida pelo facto de elas próprias serem substratos dos transportadores de recaptação da DA (DAT), 5-HT (SERT) e NA (NAT) pelo que estes são inibidos competitivamente. ${ }^{20}$ Os usos clínicos (limitados pelos seus efeitos adversos) das anfetaminas e metanfetaminas são uma consequência do seu efeito estimulante do SNC. Incluem a administração crónica para o tratamento da narcolepsia em adultos, o tratamento da síndrome de défice de atenção e hiperatividade em crianças que compromete o desempenho escolar e desenvolvimento social, e apresentam reduzida eficácia como supressores do apetite no tratamento da obesidade. $O$ facto de reduzirem a sensação de fadiga física e psíquica motiva o seu estudo em atletas e em situações militares. ${ }^{21}$

As anfetaminas e metanfetaminas existem como isómeros estruturais e estereoisómeros. Isómeros estruturais são compostos com a mesma fórmula empírica, mas um diferente arranjo atómico, por exemplo, metanfetamina e fentermina. Os estereoisómeros, nomeadamente os enantiómeros, diferem no arranjo tridimensional dos átomos ligados a pelo menos um carbono assimétrico e não são imagens sobrepostas num espelho. Portanto, a anfetamina e a metanfetamina existem em duas formas isoméricas $d$ e $l$, os quais juntos formam uma mistura racémica. A forma $d$-anfetamina tem atividade estimulante significativa, e possui cerca de 3-4 vezes a atividade central da forma $I$, a qual é mais ativa a nível periférico e é metabolito da selegilina. ${ }^{22}$

A selegilina (enantiómero $\mathrm{R}$ ) tem sido utilizada quase exclusivamente como inibidor da monoamina oxidase (MAO)$-B$, no tratamento da doença de Parkinson pois prolonga a necessidade de administração de levodopa. A selegilina é rapidamente metabolizada pelas enzimas microssomias a l-metanfetamina (por N-despropinilação), l-anfetamina (por N-desmetilação da metamfetamina), desmetilselegilina (por $\mathrm{N}$-desmetilação) e este último em $\mathrm{I}$-anfetamina por $\mathrm{N}$-despropinilação. ${ }^{23}$ Estes metabolitos ocorrem sempre como derivados levógiros ( $I$-metanfetamina e $I$-anfetamina), porque o centro quiral da selegilina não é afetado durante o metabolismo. ${ }^{23}$ Os enantiómeros $d$ de metanfetaminas e anfetaminas são comumente usados como drogas abuso. ${ }^{24}$ Portanto, a análise de metanfetaminas e anfetaminas em casos de intoxicação por selegilina é importante na prática clínica e forense para distinguir entre os casos de exposição à selegilina ou a $d$-metanfetaminas. ${ }^{23}$ Apesar deste metabolismo, não há nenhuma evidência que a selegilina seja aditiva, ${ }^{25}$ tendo mesmo sido utilizada para tratamento dos adictos por cocaína e tabaco. ${ }^{26}$ Também é importante notar que os enantiómeros $d$ e / podem ter, não só atividade farmacodinâmica diferente, mas também diferentes características farmacocinéticas.

Existem numerosos métodos descritos para a síntese de anfetaminas. Os principais métodos utilizados pelos laboratórios clandestinos, utilizam reagentes que podem ser facilmente adquiridos e/ou cujas operações químicas 
necessárias para se obterem, não são muito elaboradas. ${ }^{27}$ Classicamente utilizam l-efedrina (presentem suplementos estimulantes e para a perda de peso) ou $d$-pseudoefedrina (presentes em vários fármacos descongestionantes) puros como materiais de partida para se obter $d$-metanfetamina. Tal é simples de se conseguir, pois a pseudoefedrina e a metanfetamina são quimicamente diferentes em apenas um único átomo de oxigénio. Muito recentemente foi introduzido no mercado uma nova formulação de pseudoefedrina $\left(\right.$ Nexafed $\left.^{\circledR}\right)$ que usa uma tecnologia Impede ${ }^{\circledR}$. Esta última corresponde a uma mistura de polímeros que reduzem a extração e conversão de pseudoefedrina em metanfetamina através da formação de uma massa gelatinosa quando misturados com solventes. ${ }^{27}$ Isoladamente a $d$-pseudoefedrina é também alvo de abuso. ${ }^{28}$

\section{Ecstasy}

Neste tópico é de salientar também o derivado anfetamínico, 'ecstasy' (estruturalmente semelhante à $d$-metanfetamina e à mescalina), a qual apresenta elevado consumo na realidade Portuguesa, sobretudo no contexto de festas rave. A sua grande popularidade, apenas ultrapassada pelos derivados da Cannabis, deve-se aos seus efeitos estimulantes, ao aumento do estado de vigília, à indução de sensação de bem-estar e de sentimentos de confiança e empatia, à diminuição das inibições e a uma falsa perceção de inocuidade. ${ }^{29}$ No consumo de MDMA têm sido descritas associações com o sildenafil, tadalafil e vardenafil para aumentar o desempenho sexual entre os utilizadores desta droga, sem que tenham qualquer tipo de disfunção erétil. ${ }^{30}$ A combinação com antidepressivos e metilfenidato tem também sido descrita. ${ }^{30}$ Estas práticas de utilizar fármacos, antes, durante ou após o consumo de ecstasy acarretam óbvios riscos. ${ }^{31}$ Por exemplo alguns antidepressivos (inibidores da monoamina oxidase, inibidores seletivos da recaptação da 5-HT, etc.) associados à ecstasy podem predispor para a síndrome serotoninérgica, o qual é potencialmente fatal. ${ }^{32}$ Há um risco também acrescido de os indivíduos terem relações sexuais com um maior número de parceiros durante um maior período de tempo e como tal possibilidade de contraírem infeções sexualmente transmissíveis. ${ }^{33,34}$

\section{Metilfenidato}

O metilfenidato é um outro derivado anfetamínico indicado como psicoestimulante no tratamento adjuvante da síndrome de déficit de atenção e hiperatividade ou da narcolepsia. ${ }^{35}$ É uma mistura racémica de $d$-treo-(R,R)-metilfenidato (ou dexmetilfenidato) e 1 -treo-(S,S)- metilfenidato, sendo o enantiómero $d$ implicado nas ações terapêuticas do fármaco, bem como nos seus efeitos secundários indesejáveis, incluindo os seus efeitos adversos, nomeadamente aumento da pressão arterial e anorexígenos. Inibe a recaptação e estimula a libertação da DA e NA e desprezável em relação à $5-\mathrm{HT}^{35}$ Verifica-se como tal um risco de adição pois há aumento da DA na fenda sináptica. No entanto este potencial é menor que outras anfetaminas e que a cocaína pois a clearence cerebral de metilfenidato é lenta.

O metilfenidato tem sido usado ilicitamente pelos jovens em período de exames por aumentar as capacidades cognitivas. ${ }^{36}$ Também existe a crença instalada entre os jovens que a associação de metilfenidato e etanol permite que maiores doses sejam consumidas de etanol e como tal festas mais longas. ${ }^{37}$ Algumas evidências sugerem interações tanto farmacocinéticas como farmacodinâmicas. Os níveis plasmáticos de $d \mathrm{e} /$ metilfenidato tendem a ser mais elevados $^{38}$ e verifica-se a formação enantioseletiva de $/$ ou $d$-etilfenidato ${ }^{38}$ catalizada pela carboxiesterase humana-1, a qual promove a transesterificação com o etanol à semeIhança da cocaína. ${ }^{39}$

\section{Cocaína}

A cocaína é o principal alcaloide ativo existente na planta (nomeadamente nas folhas) Erythroxylon coca, um arbusto encontrado na região do Andes da América do Sul, sobretudo em zonas de altitudes entre 500 e 1500 metros..$^{40}$ Porque a quantidade cocaína presente nas folhas colhidas diminui ao longo do tempo, as folhas são geralmente transformados em pasta de cocaína e/ou pó mais o mais rapidamente possível. ${ }^{41}$ Para extrair a cocaína da planta, as folhas colhidas são maceradas com solventes, como querosene, até que uma substância pastosa (chamada de 'pasta de cocaína') seja isolada. Essa pasta, que contém 40-80\% de cocaína, é então submetida à reação com ácido clorídrico formando-se o cloridrato de cocaína (ou 'pó de cocaína'). ${ }^{42}$ Este último é solúvel em água sendo frequentemente administrado por via oral, intranasal ou parentérica. O cloridrato de cocaína apresenta um elevado ponto de fusão decompondo-se quando fumado. Quando aquecido em uma solução alcalina o cloridrato de cocaína é transformado em cocaína base livre ou em crack, os quais podem então ser fumados. Tanto a cocaína base livre como o crack apresentam a mesma estrutura química, mas diferentes características físicas e são obtidos por diferentes vias. ${ }^{41}$

Por vezes, a cocaína é adulterada com o objetivo de aumentar o seu volume ou de potenciar os seus efeitos. Nestes casos, é misturada com substâncias tais como a lactose, anestésicos locais (procaína, lidocaína ou benzocaína) e estimulantes (como anfetaminas ou cafeína), as quais podem também provocar reações adversas indesejadas nos toxicodependentes, ou mesmo à morte..$^{40,43}$

A cocaína é à semelhança de muitos antidepressivos um adrenomimético de ação indireta pois bloqueia o mecanismo de recaptação de monoaminas (DA, NA, 5-HT), potencializando a atividade desses neurotransmissores nos recetores pós-sinápticos. ${ }^{44} \mathrm{O}$ aumento da DA em determinadas áreas cerebrais, como por exemplo, no núcleo accumbens, é responsável pelos efeitos de recompensa da cocaína e pelos seus potentes efeitos aditivos. ${ }^{6}$

Se por um lado a cocaína provoca sensações de euforia e prazer, considerados sintomas 'positivos' devido à intensificação na transmissão monoaminérgica, ${ }^{44}$ por outro lado, o bloqueio prolongado da recaptação, causado pelo uso crónico desta droga de abuso, acarreta a depleção dessas 
monoaminas. ${ }^{45}$ A redução da transmissão monoaminérgica resulta em numerosos sintomas e desordens psiquiátricas como depressão, ansiedade, insónia, anedonia, impulsividade, sintomas de agressividade e síndrome de abstinência. $^{46}$

A nível periférico, a cocaína também atua como um anestésico local, devido à sua capacidade de bloquear canais de sódio dependentes da voltagem em células neuronais, bloqueando assim a propagação do potencial de ação. ${ }^{40} \mathrm{~A}$ cocaína foi de facto o primeiro anestésico local introduzido na prática médica por Koller em 1884 como anestésico tópico oftálmico, após ter sido isolada por Niemann em $1860 .{ }^{4} \mathrm{~A}$ cocaína é diferente dos outros anestésicos locais no que se refere aos seus efeitos cardiovasculares. $O$ bloqueio da recaptação de NA resulta em vasoconstrição e hipertensão, bem como arritmias cardíacas. A cocaína atua também como antiarrítmico classe I, bloqueando canais de sódio e potássio. Estes efeitos periféricos não parecem estar envolvidos na recompensa nem na adição à cocaína. ${ }^{4}$

\section{ANTIPARKINSÓNICOS ANTICOLINÉRGICOS}

A utilização terapêutica do biperideno e tri-hexifenidilo apesar de limitada, é pertinente nalguns casos (por exemplo, quando há predomínio de tremor). ${ }^{9}$ Eles competem com o neurotransmissor acetilcolina para os seus recetores nas junções sinápticas, o que consequentemente conduz a inibição da transmissão de certos impulsos nervosos. As limitações resultam, essencialmente, da sua reduzida tolerância, quer pela interferência a nível dos processos mnésicos, quer pela capacidade de induzir quadros confusionais, quer por outros sintomas e sinais, previsíveis pela interferência no sistema nervoso autónomo.

Ocasionalmente, estes medicamentos são utilizados abusivamente por toxicodependentes para indução de euforia, experiências psicadélicas e alucinogénias ou abusados por doentes em doentes esquizofrénicos para contrariar os efeitos extrapiramidais dos fármacos antipsicóticos. ${ }^{47,48}$ As reações adversas mais comuns a este grupo de fármacos incluem xerostomia; confusão mental, desorientação, alucinações, sintomas psicóticos, alterações da memória; taquicardia, palpitações e hipotensão; náuseas, vómitos, obstipação, úlcera duodenal; retenção urinária, hesitação urinária e disúria; fraqueza muscular, cãibras; pode ocorrer um efeito inibitório da lactação e ainda: aumento da temperatura, rubor, parestesias dos dedos, diminuição da sudação, dificuldade em conseguir ou manter a ereção.

\section{OPIOIDES}

A nomenclatura dos derivados do ópio tem sido alterada com o decorrer dos anos. ${ }^{49}$ Já foram denominados narcóticos, hipnoanalgésicos, e narcoanalgésicos, termos considerados hoje inadequados por incluírem outros xenobióticos que induzem o sono. Também já foram denominados opiáceos, de início uma designação genérica, e depois restrita aos alcaloides de origem natural obtidos a partir do ópio (Papaver somniferum e Papaver album) e os de origem semissintética, cujos principais são a morfina (10\%), codeína (ou metilmorfina, 0,5\%), papaverina (1\%), estes últimos com interesse clínico e a tebaína $(0,2 \%)$. São extraídos de um exsudado leitoso que escorre quando as cápsulas de sementes verdes são cortadas. Papaver é a palavra grega para papoila e somniferum é a palavra em latim para indutores do sono. ${ }^{49}$ Quando seco, o material é chamado de ópio bruto sendo a percentagem real de cada alcaloide altamente dependente das condições de crescimento e região geográfica. O termo 'opioide' foi proposto por Acheson para designar os xenobióticos com ação semelhante à da morfina, porém com estrutura química diferente..$^{50}$ Contudo, o conceito de opioide evoluiu e passou a incluir compostos relacionados com o ópio com ações do tipo ópio não estando no entanto confinados aos opiáceos. Hoje o conceito de opioides engloba xenobióticos ou endobióticos de origem natural, semissintética, sintética e endógena que interagem com os recetores opioides e que são completamente antagonizados pela naloxona, ou seja podem atuar como agonistas e antagonistas. ${ }^{50}$

Vários são os efeitos adversos descritos, mediados em grande parte pelos recetores $\mu$, nomeadamente sedação, depressão respiratória, depressão do centro da tosse, sudação, euforia, disforia, estados confusionais, insónia, agitação, medo, alucinações, sonolência, descoordenação motora, alterações do humor e miose. ${ }^{4}$ De destacar também o grande potencial para causar dependência e adição de vários membros desta classe, que não deve, no entanto, impedir que os doentes com quadros dolorosos importantes sejam adequadamente tratados. ${ }^{51,52}$

\section{Morfina, codeína, heroína e desomorfina}

A morfina continua a ser o padrão contra o qual todos os fármacos que têm ação analgésica forte são comparados. Apenas $40-50 \%$ da dose oral de morfina chega ao cérebro pois apresenta reduzida lipofilia devido a ser um composto anfotérico (possui dois grupos ácidos e básicos) que está ionizado a pH fisiológico. Apresenta efeito de primeira passagem significativo por conjugação com o ácido glucurónico. Apenas o isómero levógiro é ativo.

A codeína (ou metilmorfina) tem apenas $15 \%$ da potência analgésica da morfina e ao contrário desta causa pouca euforia e raramente desenvolve adição. A substituição do grupo hidroxilo fenólico em C3 da morfina por um grupo metilo, diminui a suscetibilidade da molécula ao metabolismo hepático de primeira passagem (pois resiste melhor à conjugação) aumentando a biodisponibilidade per os da codeína. Metaboliza-se a morfina via CYP2D6 e este metabolito é o grande responsável tanto pelo feito terapêutico como adverso (adição). ${ }^{53}$

A heroína (ou 3,6-diacetilmorfina) foi pela primeira vez sintetizada a partir da morfina em $1874 .{ }^{24}$ Mais tarde, a Bayer ${ }^{\circledR}$ publicitou em 1898 a heroína como fármaco antitússico. ${ }^{24} \mathrm{~A}$ heroína é tipicamente administrada por via intramuscular, intravenosa, snifada ou fumada. ${ }^{54-56}$ É sabido a partir de estudos in vitro que a heroína é rapidamente desacetilada a um metabolito ativo, 6-acetilmorfina, o qual é subsequentemente hidrolisado mais lentamente a morfi- 
na. ${ }^{51}$ A adição de dois grupos acetilo na molécula de morfina produz um composto mais lipófilo. ${ }^{51}$ Portanto, a heroína pode cruzar muito mais facilmente a barreira hematoencefálica mais facilmente do que seu precursor morfina contribuindo também para uma farmacodinâmica mais intensa e com um início mais imediato. ${ }^{51}$ No entanto, os recetores opioides são estéreo-específicos e a heroína mostra uma menor afinidade (devido ao impedimento estérico do grupo 3 acetil) para os recetores opioides do que os seus metabolitos não conjugados na posição 3-hidroxilo, tais como 6-acetilmorfina, morfina e morfina-6-glicuronídeo. ${ }^{57}$ Acresce ainda o facto de a heroína apresentar um tempo de semivida de cerca de 2-4 minutos o que sugere que grande parte da sua atividade seja devida ao metabolito 6-acetilmorfina que também cruza com facilidade a barreira hematoencefálica ${ }^{58,59}$ Neste sentido, a heroína é frequentemente considerada como um pró-fármaco que atua principalmente através dos seus metabolitos. O metabolito morfina-3-glicuronídeo é ativo do ponto de vista farmacológico (estando implicado em neurotoxicidade), mas não exibe afinidade para os recetores dos opioides. ${ }^{55}$ Nos últimos anos a diacetilmorfina (princípio ativo da heroína) injetável tem-se mostrado mais eficaz que a metadona no tratamento da dependência por opioides (representada pela heroína). ${ }^{60}$

Devido às semelhanças estruturais e disponibilidade legal, a morfina é uma importante fonte para a síntese ilícita de heroína, bastando para isso anidrido acético ou cloreto de acetilo para acetilar morfina isolada do ópio. Outro opioide, a codeína, tem também sido utilizada clandestinamente para a síntese da 'desomorfina das ruas' (ou 'dihidrodesoximorfina - D', krokodil (crocodilo) ou 'heroína russa'). ${ }^{61} \mathrm{~A}$ desomorfina tem também efeitos sedativos e analgésicos e é cerca de $8-10$ vezes mais potente do que a morfina. ${ }^{51}$ $\mathrm{O}$ abuso de home-made desomorfina foi pela primeira vez descrita no leste da Sibéria em 2002 mas depois espalhou-se por toda a Rússia e às vizinhas ex-repúblicas soviéticas. A desomorfina é facilmente produzida a partir de codeína, iodo e fósforo vermelho, mas quando feitos através desta forma, é altamente impura e apresenta-se contaminada com vários outros xenobióticos, nomeadamente de resíduos ácidos e alcalinos, derivados do petróleo, óleos industriais, solventes orgânicos, de fósforo vermelho, iodo e metais pesados. ${ }^{61}$ Esta mistura provoca isquemia periférica, necrose, flebite e gangrena, muitas vezes secundariamente infetadas, que frequentemente requerem intervenção cirúrgica e até amputações dos membros. ${ }^{51}$

\section{Metadona}

A metadona é um agonista $\mu$ utilizado no tratamento da dor e na dependência por opioides, sobretudo morfina e heroína. Pode ser administrada por via oral e é mais lipófila que a morfina e por vezes considerada mais letal que a própria heroína. ${ }^{62} \mathrm{~A}$ biodisponibilidade por via oral de $75 \%$ mas exibe grande variabilidade (36-100\%). A sua longa duração de ação permite estabilizar o doente evitando ou reduzindo a intensidade das recidivas. No entanto pode também (pois é agonista opioide) desenvolver adição e dependência. ${ }^{63}$ É administrada em mistura racémica sendo o $d$-enantiómero aquele que exibe maior atividade analgésica e maior tempo de semivida (38 h versus 28 h do l-enantiómero).

\section{Buprenorfina}

A buprenorfina é também um opioide sujeito a abuso mais uma vez por interação com os recetores $\mu .{ }^{4} \dot{E}$ utilizado no tratamento de substituição da dependência de opiáceos, no contexto multidisciplinar de um tratamento médico, social e psicológico. ${ }^{9}$ As reações adversas mais frequentes incluem a síndrome de abstinência (em particular quando não forem respeitados os intervalos desde a última utilização de heroína ou outros opiáceos, incluindo metadona), cefaleias, insónia, obstipação e náuseas. Pode causar depressão respiratória fatal, em particular quando são associados benzodiazepinas, álcool ou outros opiáceos. ${ }^{64}$

\section{Tramadol}

O tramadol é um análogo sintético da codeína e agonista parcial dos recetores $\mu$ (a sua afinidade para o recetor $\mu$-opioide é apenas $1 / 6000$ da morfina). Grande parte do seu efeito analgésico é conseguido por inibição da recaptação da 5-HT e NA. ${ }^{65,66}$ Tal como os opioides tradicionais exibe também efeito aditivo, ${ }^{67}$ apesar de em geral ser apresentar melhor perfil de efeitos adversos. É administrado na forma de uma mistura racémica e ambos os diaesterioisómeros são $O$-desmetilados. Ambos os enantiómeros $d$ e $I$ do tramadol contribuem para o efeito analgésico, mas este é sobretudo conseguido pela metabolização, via CYP2D6, a O-desmetiltramadol, o qual é mais ativo que o tramadol (sobretudo o $d$-O-desmetiltramadol) e tem uma afinidade para o recetor $\mu$ apenas 10 vezes inferior à morfina. ${ }^{68} \mathrm{~A}$ depressão respiratória é possível sobretudo com metabolizadores ultrarrápidos para a CYP2D6. ${ }^{68}$

Risco importante de síndrome serotoninérgica existe na associação do tramadol com inibidores da recaptação da 5-HT (como a fluoxetina, paroxetina, e em menor extensão a sertralina). Estes antidepressivos para além de aumentarem os níveis de 5-HT no encéfalo inibem a CYP2D6 e consequentemente o metabolismo e eliminação do tramadol. ${ }^{69}$ A síndrome serotoninérgica foi também observada na associação do tramadol com inibidores da monoamina oxidase, dextrometorfano, MDMA, olanzapina, risperidona e venlafaxina ${ }^{69}$ Esta é caracterizada por sinais e sintomas disautonómicos, cognitivos e somáticos como arritmias, hipertermia, taquicardia, taquipneia, hiperreflexia, diaforese, midríase, hipertensão arterial, rigidez muscular, mioclonias, tremores, agitação extrema, diarreia, convulsões, hipertonia e pode ser fatal. ${ }^{69}$

\section{Dextrometorfano}

O dextrometorfano tem núcleo morfinamo e por esse motivo é discutido por conveniência neste tópico. Tem sido descrita a sua utilização como droga recreativa ${ }^{70}$ e facilitadora da agressão sexual. ${ }^{11} \mathrm{Na}$ terapêutica tem sido utilizado como antitússico não opioide (sem afinidade para os recetores mu e delta; logo os seus efeitos não são 
antagonizados pela naloxona e não apresenta efeito obstipante), como adjuvante dos opioides no tratamento da dor e como possível antidepressivo de rápido início de ação. ${ }^{71}$ É inibidor não seletivo da recaptação da 5-HT, estimula a libertação de 5-HT e agonista dos recetores sigma-1. É também antagonista dos recetores $\mathrm{N}$-metil-D-aspartato (também o seu metabolito dextrorfano) e em doses elevadas (superiores a $15 \mathrm{mg} / \mathrm{Kg}$ - comparável a doses elevadas de cetamina) pode mesmo exercer efeitos alucinogénios dissociativos como a cetamina e a fenciclidina. Com estas doses, os consumidores reportam ter experimentado completa dissociação mente do $\operatorname{corpo}^{70}$ podendo resultar em comportamentos violentos como descrito em vários casos. $^{72}$ Está também descrito o risco de síndrome serotoninérgica em associação com outros inibidores da recaptação da 5-HT ou na presença de inibidores da CYP2D6.

\section{ALUCINOGÉNIOS}

Representam um grupo de xenobióticos não aditivos, ou seja, exibem mecanismos de ação que não estão relacionados com a ativação ou inibição do sistema de recompensa da DA, também não induzem dependência e não são usados de modo compulsivo nem por períodos prolongados. ${ }^{4,7}$ São drogas capazes de alterar a perceção da realidade, humor e pensamento em baixas doses, sem causarem marcada estimulação psicomotora ou depressão. São assim designados porque provocam alucinações, mas nem sempre tal ocorre. Uma designação mais correta é de psicotomiméticos (mimetizam psicoses) porque a maioria destes xenobióticos têm em comum alterarem a consciência de forma imprevisível e em doses elevadas provocam perda da realidade, desorientação no tempo, despersonalização, delírio e alucinações. ${ }^{7}$

A utilização é episódica, o que é distinta das outras drogas de abuso. A maioria exerce os seus efeitos alucinogénios por serem agonistas ou agonistas parciais nos recetores $5-\mathrm{HT}$, sobretudo o $5-\mathrm{HT}_{2 \mathrm{~A}}$, mas nem todos, como se expõe na continuidade as diferenças. Os principais representantes deste grupo organizam-se em três classes que se distinguem na relação estrutural com neurotransmissores:

a) Não relacionados com a estrutura de neurotransmissores (e.g. fenciclidina e cetamina) - estes compostos foram originalmente desenvolvidos como anestésicos gerais dissociativos, ou seja capazes de promoverem perda sensorial e analgesia, amnésia e paralisia, intensa sensação de dissociação do meio, mas sem perda real da consciência e dos reflexos protetores. ${ }^{73}$ Apenas a cetamina está ainda disponível na terapêutica (dispensada em farmácia comunitária com anestésico de uso veterinário), devido à elevada frequência de delírios e alucinações observados no pós-operatório com PCP. Bloqueiam sobretudo os efeitos excitatórios do glutamato ao nível dos seus recetores $\mathrm{N}$-metil-D-aspartato de um modo não competitivo (logo diminuem a entrada de $\mathrm{Ca}^{2+}$ nas células) e deste modo interagem com o etanol. ${ }^{74}$ Pelo facto de não causar uma depressão correspondente de reflexos autonómicos e centros vitais do cérebro, ${ }^{75}$ faz da cetamina uma poderosa droga facilitadora de agressões sexuais. ${ }^{11}$ Os efeitos adversos mais clássicos da cetamina é o delírio, alucinações, taquicardia depressão respiratória leve, confusão, irracionalidade, comportamento violento ou agressivo, vertigem, ataxia, fala arrastada, tempo de reação retardado, euforia, imagem corporal alterada, analgesia, amnésia e coma ${ }^{73}$

b) Feniletilaminas ou semelhantes a NA (e.g. mescalina presente nos botões do cato peiote) os quais são altamente seletivos para os recetores $5-\mathrm{HT}_{2}\left(5-\mathrm{HT}_{2 \mathrm{~A}}\right.$, $5-\mathrm{HT}_{2 \mathrm{~B}}$, e $5-\mathrm{HT}_{2 \mathrm{C}}$ );

c) Triptaminas (ou indolaminas) ou semelhantes à $5-\mathrm{HT}$, as quais podem ainda ser divididas em:

- Triptaminas simples ou indolalquilaminas que exibem flexibilidade conformacional (e.g. psilocibina e psilocina tipicamente presentes nos 'cogumelos mágicos'). São relativamente não seletivos para os recetores 5-HT, exibindo moderada a elevada seletividade para os $5-\mathrm{HT}_{1 \mathrm{~A}}$ e $5-\mathrm{HT}_{2 \mathrm{~A}}$;

- Ergolinas que exibem rigidez conformacional (e.g. LSD). A $d$-LSD é o mais potente alucinogénio conhecido o qual atua como agonista ou agonista parcial nos recetores pré-sinápticos $5-\mathrm{HT}_{1 \mathrm{~A}}$ e $4-\mathrm{HT}_{1 \mathrm{~B}} \mathrm{e}$ nos pós-sinápticos $5-\mathrm{HT}_{2 \mathrm{~A}}{ }^{76}$. A LSD foi pela primeira vez semi-sintetizada por Albert Hofmann em 1938 a partir de ergotamina, um alcaloide produzido por um fungo filamentoso Claviceps purpurea que infesta cereais, sobretudo o arroz, centeio e milho durante o crescimento e após colheita ${ }^{77}$. Particularmente importante é a síntese ilícita da LSD que usa ácido lisérgico como reagente. Este último é produzido por laboratórios clandestinos utilizando ergotamina ou ergometrina disponível em vários medicamentos. O refluxo de ergotamina com uma solução de hidróxido de potássio e hidrazina em uma mistura de álcool-água produz ácido lisérgico. Os grandes problemas são o facilitar o suicídio, homicídio, acidentes, taquicardia, hipertensão, euforia, alucinações e sinestesias. ${ }^{78}$

\section{CANABINOIDES}

Mais de 61 canabinoides estão identificados entre os mais de 400 compostos documentados na Cannabis sativa. ${ }^{79}$ Os mais importantes são o delta-9-tetrahidrocanabinol ( $\Delta^{9}$ - THC; principal constituinte psicoativo), $\Delta^{8}$-THC (quase tão ativo como o anterior, mas em menores concentrações), canabinol (pouco ativo, mas em elevadas concentrações) e o canabidiol (não psicoativo, mas em elevadas concentrações). Diferentes partes da planta contêm diferentes concentrações de $\Delta^{9}$-THC e a potência do derivado (e.g. marijuana, haxixe, óleo de haxixe) é caracterizada pela percentagem deste xenobiótico. ${ }^{80}$

Os efeitos farmacodinâmicos (e.g. sedação, euforia, alucinações e distorção temporal) são sobretudo efetivados por ações agonistas ou antagonistas nos recetores (CB) 
em locais específicos. ${ }^{81} \mathrm{O}$ efeito antiemético do THC é também, em parte não mediado por recetores, o que justifica o uso clínico do THC em crianças (menor densidade de recetores $\mathrm{CB}_{1}$ no cérebro comparativamente aos adultos) como antiemético na quimioterapia, pois toleram doses mais elevadas. ${ }^{82}$ Até ao momento, dois recetores de canabinoides endógenos foram identificados, os recetores $\mathrm{CB}_{1}$ (ou centrais) e os recetores $\mathrm{CB}_{2}$ (ou periféricos), ambos acoplados a proteínas $\mathrm{G}$ (especificamente proteínas $\mathrm{G}_{\mathrm{i} / \mathrm{o}}$ ), que inibem a adenilciclase e estimulam a proteína quinase ativadora do mitogénio. ${ }^{83}$ Tal como os opioides, o THC causa desinibição dos neurónios dopaminérgicos, sobretudo por inibição pré-sináptica dos neurónios gabaérgicos da VTA, resultando numa menor libertação de GABA. Uma descrição mais detalhada destes recetores e sua sinalização intracelular pode ser encontrada no trabalho de Howlett et al. ${ }^{83}$

Os recetores $\mathrm{CB}_{1}$ apesar de expressos em algumas células e tecidos não neuronais (e.g. glândula hipofisária, células imunitárias e tecidos do sistema reprodutor, urinário e gastrointestinal) são sobretudo encontrados em neurónios do cérebro, medula espinhal e sistema nervoso periférico, onde medeiam a inibição da libertação de neurotransmissores em funções relacionadas com a estimulação do apetite (hipotálamo), alterações da memória (córtex e hipocampo), alterações motoras (gânglios da base, cerebelo e substância nigra), distúrbios emocionais (amiglada) e prazer (sistema de recompensa; embora este seja classificado como reduzido). ${ }^{84} \mathrm{~A}$ aparente ausência de recetores no tronco cerebral pode explicar a baixa toxicidade e como tal reduzido potencial para sobredosagem.

Os recetores $\mathrm{CB}_{2}$ ocorrem principalmente em células do sistema imunológico, entre os quais nos leucócitos, baço e amígdalas, onde modulam a libertação de citoquinas, ${ }^{84}$ e há nitidamente mais mRNA para $\mathrm{CB}_{2}$ que para $\mathrm{CB}_{1}$ no sistema imunológico. Como tal estão implicados na disfunção (inibição) do sistema imunitário onde o THC atua como agonista parcial. No entanto os recetores $\mathrm{CB}_{2}$ também já forma descritos no sistema nervoso, nomeadamente nas células de microglia. ${ }^{83}$

Os agonistas dos recetores $\mathrm{CB}_{1}$, como o dronabinol (designação para a forma sintética do $\Delta^{9}$-THC) e a nabilona (mistura racémica) estão licenciados para uso clínico em alguns países como estimulantes do apetite (dronabinol) e antieméticos na quimioterapia (ambos os fármacos). Os agonistas do recetor $\mathrm{CB}_{1}$ apresentam outros usos potenciais, nomeadamente no tratamento do glaucoma (como anti-hipertensores), dor, certos tipos de cancro e vários tipos de disfunção motora associada à esclerose múltipla ou a lesões da medula espinhal. ${ }^{84}$ Particularmente convincentes são os resultados pré-clínicos e clínicos que suportam o uso de agonistas do recetor $\mathrm{CB}_{1}$ no tratamento da dor neuropática e na melhoria da espasticidade, espasmos musculares, tremor ou dor associada à esclerose múltipla ou de lesões na medula espinhal. ${ }^{84}$ Recentemente, em 2013 foi aprovado pela Food and Drug Administration (FDA) o canabidiol (agonista dos recetores $\mathrm{CB}_{1}$ e $\mathrm{CB}_{2}$; principal com- ponente não psicoativo da Cannabis) para o tratamento de algumas formas de epilepsia pediátrica, refratárias às terapêuticas habituais. A existência de sinais prévios de adição a canabinoides limita as utilizações terapêuticas.

O rimonabanto é um antagonista (ou agonista inverso) dos recetores $\mathrm{CB}_{1}$ (cerca 1000 vezes maior afinidade que para $\mathrm{CB}_{2}$ ) que estava indicado sobretudo para o tratamento da obesidade ${ }^{85}$ mas também da dependência pelo tabaco pois bloqueia a libertação de DA no núcleo accumbens (um dos centros primários de recompensa). ${ }^{86}$

Agonistas seletivos do recetor $\mathrm{CB}_{2}$ estão a ser desenvolvidos nomeadamente como analgésicos, anti-inflamatórios, antineoplásicos e no alívio da dor neuropática. ${ }^{87}$

\section{LEGAL HIGHS OU HERBAL HIGHS OU SMARTDRUGS}

$\mathrm{Na}$ atualidade assistimos a uma nova tendência no consumo de drogas, com o aparecimento diariamente no mercado de substâncias psicoativas não controladas pela legislação vigente, as quais têm sido designadas como smartdrugs ou legalhighs ou herbalhighs ('herbal' - logo 'mais seguros'). ${ }^{88,89}$ Estas drogas estabeleceram-se rapidamente como alternativas ao consumo das drogas ilegais pela mimetização dos seus efeitos, principalmente em contextos recreativos, mas sem que a segurança toxicológica seja garantida (muito pelo contrário).

Dentro deste grupo dá-se particular destaque aos derivados pierazínicos, com efeitos semelhantes a anfetaminas e derivados como a ecstasy. A piperazina foi originalmente utilizada como anti-helmíntico e ainda hoje tem aplicação na terapêutica humana e veterinária. ${ }^{90}$ Posteriormente vários fármacos (e.g. sildenafil, vardenafil, trazodona, nefazodona, clozapina e olanzapina), mas também drogas recreativas (1-benzilpiperazina) incluíram o núcleo piperazina na sua estrutura. A benzilpiperazina é sintetizada ilicitamente a partir da piperazina e à semelhança das anfetaminas e derivados, apresenta efeitos anorexigénios, estimulantes, promovendo o aumento da confiança, desinibição, euforia, atividade física e socialização. ${ }^{90}$

Uma das legal highs naturais mais utilizadas é o Kratom, uma mistura de alcaloides com potente atividade opioide (e.g. mitraginina e a 7-hidroximitraginina) extraídos da planta Mitragyna speciosa. ${ }^{91}$ Aos extratos das folhas da planta são muitas vezes adicionados outros compostos para potenciar os seus efeitos psicoativos, como é o caso do metabolito ativo do tramadol, o O-desmetiltramadol. ${ }^{92}$ Esta mistura é conhecida e vendida na Internet como Krypton e pode ser fatal. ${ }^{92}$

\section{CONCLUSÕES}

Esta revisão explora o potencial ilícito de alguns xenobióticos, muitos dos quais utilizados primeiramente como fármacos. Sempre que adequado a capacidade aditiva dessas substâncias foi discutida. Neste particular, o neurotransmissor do 'prazer', DA, está amplamente reconhecido como sendo critico na neurobiologia da recompensa, aprendizagem e adição, ${ }^{93}$ mas a exata função desta tem sido também contestada e revista. ${ }^{94}$ Virtualmente todas as 
drogas de abuso ativam as vias dopaminérgicas por mecanismos diversos com exceção dos alucinogénios como já foi anteriormente discutido. As recompensas 'naturais' como a alimentação, interações sociais positivas, jogar, brincar, interações sexuais, ouvir música e o humor, ativam de igual modo os neurónios dopaminérgicos. ${ }^{94}$

Por último, importa discutir alguns pontos-chave da Lei n. ${ }^{\circ} 30 / 2000$ de 20 de novembro, a qual define o regime jurídico aplicável ao consumo de estupefacientes e substâncias psicotrópicas, bem como a proteção sanitária e social das pessoas que consomem tais substâncias sem prescrição médica. A opção portuguesa é de descriminalizar o consumo de drogas (e/ou a posse para consumo), referindo no seu artigo segundo que "o consumo, a aquisição e a detenção para consumo próprio de plantas, substâncias ou preparações compreendidas nas tabelas" constituem contraordenação. É importante perceber que, para efeitos da presente lei, a aquisição e a detenção para consumo próprio das substâncias referidas no artigo anterior não poderão exceder a quantidade necessária para o consumo médio individual durante o período de 10 dias. Por vezes associa-se a descriminalização a qualquer forma de mitigação de penas (despenalização), mas é o afastamento de qualquer tipo de penalidade de natureza criminal e, consequentemente, a impossibilidade de aplicação de penas de prisão para os ilícitos de consumo que melhor a caracteriza. A Lei em causa mantém na sua essência a proibição (é contraordenação) do uso de qualquer tipo de substância

\section{REFERÊNCIAS}

1. United Nations Office on Drugs and Crime. World Drug Report 2010. Vienna: United Nations Publication; 2010.

2. Chakravarthy $B$, Shah S, Lotfipour S. Adolescent drug abuse awareness \& prevention. Indian J Med Res. 2013;137:1021-3.

3. Belcher HM, Shinitzky HE. Substance abuse in children: prediction, protection, and prevention. Arch Pediatr Adolesc Med. 1998;152:95260.

4. Katzung BG, Masters SB, Trevor AJ editors. Basic \& Clinical Pharmacology. $2^{\text {nd }}$ ed. New York: McGraw-Hill Medical; 2012.

5. Veenhoven R. Hedonism and happiness. J Happiness Studies. 2003;4:437-57.

6. Golan DE, Tashjian J, Armstrong EJ, Armstrong AW. Principles of pharmacology: the pathophysiologic basis of drug therapy. $3^{\text {rd }}$ ed. Philadelphia: Lippincott Williams \& Wilkins; 2012.

7. Brunton LL, Chabner BA, Knollmann BC. Goodman \& Gilman's. The pharmacological basis of therapeutics. $11^{\text {th }}$ ed. New York: McGraw-Hill Medical Publishing Division; 2011.

8. Dinis-Oliveira RJ, Nunes R, Carvalho F, Santos A, Teixeira H, Vieira $\mathrm{DN}$, et al. Procedimentos técnicos, éticos e legais da competência do médico no cumprimento da lei da fiscalização da condução rodoviária sob influência do álcool e substâncias psicotrópicas. Acta Med Port. 2010;23:1059-82.

9. Autoridade Nacional do Medicamento e Produtos de Saúde. Minist'rio da Saúde. Prontuário Terapêutico - 11. Lisboa: Autoridade Nacional do Medicamento e Produtos de Saúde, Ministério de Saúde; 2012.

10. Hall JA, Moore CB. Drug facilitated sexual assault-a review. J Forensic Leg Med. 2008;15:291-7.

11. Dinis-Oliveira RJ, Magalhaes T. Forensic toxicology in drug-facilitated sexual assault. Toxicol Mech Methods. 2013;23:471-8.

12. Society of Forensic Toxicologists (SOFT) - Drug-Facilitated Sexual Assault Committee. Recommended Maximum Detection Limits for Common DFSA Drugs and Metabolites in Urine Samples. Mesa: SOFT; 2005.

13. Harper NS. Drug-facilitated sexual assault. In: Jenny C editor. Child abuse and neglect: diagnosis, treatment and evidence. Amsterdam: ilegal. Contudo, retira da alçada do direito penal a proibição legal das transgressões e cria um novo sistema sancionatório a aplicar por uma nova instância extrajudiciária - as Comissões de Dissuasão da Toxicodependência.

No final desta revisão importa esclarecer que não se pretendeu uma discussão exaustiva dos diferentes mecanismos farmacodinâmicos, até porque muitos deles estão ainda mal caracterizados. Isto implica, que todas as generalizações são arriscadas. Foi objetivo dar enfâse aos dados perfeitamente comprovados e aceites pelos pares, deixando sempre a noção de que o leitor deverá aprofundar características particulares de cada umas das drogas de abuso consultando a bibliografia citada. Acresce ainda o facto, de a toxicodependência ser uma doença neurológica (e não um comportamento criminoso ou uma desordem do comportamento) multifatorial podendo ter variáveis relacionadas com o agente (droga de abuso), hospedeiro (toxicodependente), e o ambiente. ${ }^{4}$ Por último foi também objetivo alertar para os potenciais ilícitos de alguns grupos farmacológicos.

\section{CONFLITOS DE INTERESSE}

$\mathrm{O}$ autor declara não ter qualquer conflito de interesse relativamente ao presente artigo.

\section{FONTES DE FINANCIAMENTO}

Este trabalho não recebeu qualquer contribuição e subsídio ou bolsa.

Elsevier; 2011.p.118-26.

14. Schwartz $\mathrm{RH}$, Weaver $A B$. Rohypnol, the date rape drug. Clin Pediatr. 1998;37:321.

15. LeBeau MA. Drug-facilitated sexual assault: a forensic handbook. San Diego: Academic Press; 2001.

16. Schep LJ, Knudsen K, Slaughter RJ, Vale JA, Megarbane B. The clinical toxicology of gamma-hydroxybutyrate, gamma-butyrolactone and 1,4-butanediol. Clin Toxicol. 2012;50:458-70.

17. Alshaikh MK, Tricco AC, Tashkandi M, Mamdani M, Straus SE, BaHammam AS. Sodium oxybate for narcolepsy with cataplexy: systematic review and meta-analysis. J Clin Sleep Med. 2012;8:451-8.

18. Carvalho M, Carmo H, Costa VM, Capela JP, Pontes H, Remiao F, et al. Toxicity of amphetamines: an update. Arch Toxicol. 2012;86:1167-231.

19. Dinis-Oliveira RJ, Caldas I, Carvalho F. Magalhaes T. Bruxism after 3,4-methylenedioxymethamphetamine (ecstasy) abuse. Clin Toxicol. 2010;48:863-4.

20. Schep LJ, Slaughter RJ, Beasley DM. The clinical toxicology of metamfetamine. Clin Toxicol. 2010;48:675-94.

21. Gore RK, Webb TS, Hermes ED. Fatigue and stimulant use in military fighter aircrew during combat operations. Aviat Space Environ Med. 2010;81:719-27.

22. Magyar K. The pharmacology of selegiline. Int Rev Neurobiol. 2011;100:65-84

23. Fujita $\mathrm{Y}$, Takahashi $\mathrm{K}$, Takei M, Niitsu $\mathrm{H}$, Aoki $\mathrm{Y}$, Onodera M, et al. Detection of levorotatory methamphetamine and levorotatory amphetamine in urine after ingestion of an overdose of selegiline. Yakugaku Zasshi. 2008;128:1507-12.

24. Karch SB. Pharmacokinetics and pharmacodynamics of abused drugs. Boca Raton: CRC Press; 2008.

25. Schneider LS, Tariot PN, Goldstein B. Therapy with I-deprenyl (selegiline) and relation to abuse liability. Clin Pharmacol Ther. 1994;56:750-6.

26. Harris DS, Everhart T, Jacob P 3rd, Lin E, Mendelson JE, Jones RT. A phase 1 trial of pharmacologic interactions between transdermal selegiline and a 4-hour cocaine infusion. BMC Clin Pharmacol. 2009;9:13. 
27. Brzeczko AW, Leech R, Stark JG. The advent of a new pseudoephedrine product to combat methamphetamine abuse. Am J Drug Alcohol Abuse. 2013;39:284-90.

28. Sullivan G. Acute psychosis following intravenous abuse of pseudoephedrine: a case report. J Psychopharmacol. 1996;10:324-5.

29. GreenAR, MechanAO, ElliottJM, O'SheaE, Colado MI. The pharmacology and clinical pharmacology of 3,4-methylenedioxymethamphetamine (MDMA, 'ecstasy'). Pharmacol Rev. 2003;55:463-508.

30. Silins E, Copeland J, Dillon P. Patterns and harms of pharmaceutical drug use among ecstasy users in Australia. Adicciones. 2009;21:347-62.

31. Copeland J, Dillon P, Gascoigne M. Ecstasy and the concomitant use of pharmaceuticals. Addict Behav. 2006;31:367-70.

32. Gillman PK. A review of serotonin toxicity data: implications for the mechanisms of antidepressant drug action. Biol Psychiatry. 2006;59:1046-51.

33. Swearingen SG, Klausner JD. Sildenafil use, sexual risk behavior, and risk for sexually transmitted diseases, including HIV infection. Am J Med. 2005;118:571-7.

34. Romanelli F, Smith KM. Recreational use of sildenafil by HIV-positive and -negative homosexual/bisexual males. Ann Pharmacother. 2004;38:1024-30.

35. Scharman EJ, Erdman AR, Cobaugh DJ, Olson KR, Woolf AD, Caravati EM, et al. Methylphenidate poisoning: an evidence-based consensus guideline for out-of-hospital management. Clin Toxicol. 2007;45:737-52.

36. Harris $\mathrm{J}$. Is it acceptable for people to take methylphenidate to enhance performance? Yes. BMJ. 2009;338:b1955.

37. Godfrey J. Safety of therapeutic methylphenidate in adults: a systematic review of the evidence. J Psychopharmacol. 2009;23:194-205.

38. Patrick KS, Straughn AB, Minhinnett RR, Yeatts $S D$, Herrin AE, DeVane $\mathrm{CL}$, et al. Influence of ethanol and gender on methylphenidate pharmacokinetics and pharmacodynamics. Clin Pharmacol Ther. 2007;81:346-53.

39. Kimko HC, Cross JT, Abernethy DR. Pharmacokinetics and clinical effectiveness of methylphenidate. Clin Pharmacokinet. 1999;37:457-70.

40. Goldstein RA, DesLauriers C, Burda AM. Cocaine: history, social implications, and toxicity-a review. Dis Mon. 2009;55:6-38.

41. Warner EA. Cocaine abuse. Ann Intern Med. 1993;119:226-35.

42. Shannon M. Clinical toxicity of cocaine adulterants. Ann Emerg Med. 1988; $17: 1243-7$

43. Dinis-Oliveira RJ, Carvalho F, Duarte JA, Proenca JB, Santos A, Magalhaes T. Clinical and forensic signs related to cocaine abuse. Curr Drug Abuse Rev. 2012;5:64-83.

44. Reith ME, Li MY, Yan QS. Extracellular dopamine, norepinephrine, and serotonin in the ventral tegmental area and nucleus accumbens of freely moving rats during intracerebral dialysis following systemic administration of cocaine and other uptake blockers. Psychopharmacology. 1997;134:309-17.

45. Menon DV, Wang Z, Fadel PJ, Arbique D, Leonard D, Li JL, et al. Central sympatholysis as a novel countermeasure for cocaine-induced sympathetic activation and vasoconstriction in humans. J Am Coll Cardiol. 2007;50:626-33.

46. Kramer LD, Locke GE, Ogunyemi A, Nelson L. Cocaine-related seizures in adults. Am J Drug Alcohol Abuse. 1990;16:307-17.

47. Petkovic S, Durendic-Brenesel M, Dolai M, Samojlik I. Fatal intoxication because of trihexyphenidyl. J Forensic Sci. 2011;56:1383-6.

48. Nappo SA, de Oliveira LG, Sanchez Z, Carlini Ede A. Trihexyphenidyl (Artane): a Brazilian study of its abuse. Subst Use Misuse. 2005;40:47382.

49. Freye E, Levy JV, editors. Opioids in medicine: a comprehensive review on the mode of action and the use of analgesics in different clinical pain states. Dordrecht: Springer; 2008.

50. Martin WR. Pharmacology of opioids. Pharmacol Ver. 1983;35:283-323.

51. Dinis-Oliveira RJ, Carvalho F, Moreira R, Duarte JA, Proenca JB, Santos $A$, et al. Clinical and forensic signs related to opioids abuse. Curr Drug Abuse Rev. 2012;5:273-90.

52. Negus SS, Banks ML. Medications development for opioid abuse. Cold Spring Harb Perspect Med. 2013;3:a012104.

53. Trescot AM, Datta S, Lee M, Hansen H. Opioid pharmacology. Pain Physician. 2008;11:S133-53.

54. Cone EJ, Holicky BA, Grant TM, Darwin WD, Goldberger BA. Pharmacokinetics and pharmacodynamics of intranasal 'snorted' heroin. J Anal Toxicol. 1993;17:327-37.

55. Smith ML, Shimomura ET, Summers J, Paul BD, Jenkins AJ, Darwin WD, et al. Urinary excretion profiles for total morphine, free morphine, and 6-acetylmorphine following smoked and intravenous heroin. J Anal Toxicol. 2001;25:504-14.
56. Jenkins AJ, Keenan RM, Henningfield JE, Cone EJ. Pharmacokinetics and pharmacodynamics of smoked heroin. J Anal Toxicol. 1994;18:31730 .

57. Selley DE, Cao CC, Sexton T, Schwegel JA, Martin TJ, Childers SR. mu Opioid receptor-mediated G-protein activation by heroin metabolites: evidence for greater efficacy of 6-monoacetylmorphine compared with morphine. Biochem Pharmacol. 2001;62:447-55.

58. Gyr E, Brenneisen R, Bourquin D, Lehmann T, Vonlanthen D. Hug I. Pharmacodynamics and pharmacokinetics of intravenously, orally and rectally administered diacetylmorphine in opioid dependents, a twopatient pilot study within a heroin-assisted treatment program. Int J Clin Pharmacol Ther. 2000;38:486-91.

59. Rook EJ, Huitema AD, van den Brink W, van Ree JM, Beijnen JH. Pharmacokinetics and pharmacokinetic variability of heroin and its metabolites: review of the literature. Curr Clin Pharmacol. 2006;1:10918.

60. Oviedo-Joekes E, Brissette S, Marsh DC, Lauzon P, Guh D, Anis A, et al. Diacetylmorphine versus methadone for the treatment of opioid addiction. N Engl J Med. 2009;361:777-86.

61. Skowronek R, Celinski R, Chowaniec C. 'Crocodile' - new dangerous designer drug of abuse from the East. Clin Toxicol. 2012;50:269.

62. Meyer MR, Maurer HH. Absorption, distribution, metabolism and excretion pharmacogenomics of drugs of abuse. Pharmacogenomics. 2011;12:215-33.

63. Kapur BM, Hutson JR, Chibber T, Luk A, Selby P. Methadone: a review of drug-drug and pathophysiological interactions. Crit Rev Clin Lab Sci. 2011;48:171-95.

64. Lavonas EJ, Banner W, Bradt P, Bucher-Bartelson B, Brown KR, Rajan $P$, et al. Root causes, clinical effects, and outcomes of unintentional exposures to buprenorphine by young children. J Pediatr. 2013;163:1377-83.e1-3.

65. Costa I, Oliveira A, Guedes de Pinho P, Teixeira HM, Moreira R, Carvalho F, et al. Postmortem redistribution of tramadol and O-desmethyltramadol. J Anal Toxicol. 2013;37:670-5.

66. Pinho S, Oliveira A, Costa I, Gouveia CA, Carvalho F, Moreira RF, et al. Simultaneous quantification of tramadol and O-desmethyltramadol in hair samples by gas chromatography-electron impact/mass spectrometry. Biomed Chromatogr. 2013;27:1003-11.

67. Mehrpour O. Addiction and seizure ability of tramadol in high-risk patients. Indian J Anaesth. 2013;57:86-7.

68. Grond S, Sablotzki A. Clinical pharmacology of tramadol. Clin Pharmacokinet. 2004;43:879-923.

Sansone RA, Sansone LA. Tramadol: seizures, serotonin syndrome, and coadministered antidepressants. Psychiatry. 2009;6:17-21.

69. Boyer EW. Dextromethorphan abuse. Pediatr Emerg Care. 2004;20:85863.

70. Schwartz RH. Adolescent abuse of dextromethorphan. Clin Pediatr. $2005 ; 44: 565-8$

71. Logan BK, Yeakel JK, Goldfogel G, Frost MP, Sandstrom G, Wickham DJ. Dextromethorphan abuse leading to assault, suicide, or homicide. J Forensic Sci. 2012;57:1388-94.

72. Morgan CJ, Curran HV. Ketamine use: a review. Addiction. 2012;107:2738

73. Dinis-Oliveira RJ, Carvalho F, Duarte JA, Dias R, Magalhaes T, Santos A. Suicide by hanging under the influence of ketamine and ethanol. Forensic Sci Int. 2010;202:e23-7.

74. Shbair MK, Eljabour S, Lhermitte M. Drugs involved in drug-facilitated crimes: part I: alcohol, sedative-hypnotic drugs, gamma-hydroxybutyrate and ketamine. A review. Ann Pharm Fr. 2010;68:275-85.

75. Schiff PL. Ergot and its alkaloids. Am J Pharm Educ. 2006;70:98.

76. Passie T, Halpern JH, Stichtenoth DO, Emrich HM, Hintzen A. The pharmacology of lysergic acid diethylamide: a review. CNS Neurosci Ther. 2008;14:295-314

77. Gillman PK. Triptans, serotonin agonists, and serotonin syndrome (serotonin toxicity): a review. Headache. 2010;50:264-72.

78. Ross SA, EISohly MA, Sultana GN, Mehmedic Z, Hossain CF, Chandra $S$. Flavonoid glycosides and cannabinoids from the pollen of Cannabis sativa L. Phytochem Anal. 2005;16:45-8.

79. Sharma P, Murthy P, Bharath MM. Chemistry, metabolism, and toxicology of cannabis: clinical implications. Iran J Psychiatry. 2012;7:149-56.

80. Grotenhermen F. Pharmacokinetics and pharmacodynamics of cannabinoids. Clin Pharmacokinet. 2003;42:327-60.

81. Abrahamov A, Mechoulam R. An efficient new cannabinoid antiemetic in pediatric oncology. Life Sci. 1995;56:2097-102.

82. Howlett AC, Barth F, Bonner TI, Cabral G, Casellas P, Devane WA, et al. International Union of Pharmacology. XXVII. Classification of 
cannabinoid receptors. Pharmacol Rev. 2002:54:161-202.

83. Pertwee RG. Pharmacological actions of cannabinoids. Handb Exp Pharmacol. 2005;1-51.

84. Pi-Sunyer FX, Aronne LJ, Heshmati HM, Devin J, Rosenstock J. Effect of rimonabant, a cannabinoid-1 receptor blocker, on weight and cardiometabolic risk factors in overweight or obese patients: RIO-North America: a randomized controlled trial. JAMA. 2006;295:761-75.

85. Garwood CL, Potts LA. Emerging pharmacotherapies for smoking cessation. Am J Health Syst Pharm. 2007;64:1693-8.

86. Malan TP Jr, Ibrahim MM, Vanderah TW, Makriyannis A, Porreca F. Inhibition of pain responses by activation of $\mathrm{CB}(2)$ cannabinoid receptors. Chem Phys Lipids. 2002;121:191-200.

87. Ribeiro E, Magalhaes T, Dinis-Oliveira RJ. Mefedrona, a nova droga de abuso: farmacocinética, farmacodinâmica e implicações clínicas e forenses. Acta Med Port. 2012;25:111-7.
88. Johnson LA, Johnson RL, Portier RB. Current 'legal highs'. J Emerg Med. 2013;44:1108-15.

89. Monteiro MS, Bastos Mde L, Guedes de Pinho P, Carvalho M. Update on 1-benzylpiperazine (BZP) party pills. Arch Toxicol. 2013;87:929-47.

90. Observatório Europeu das Drogas e da Toxicodependência. Novas drogas e tendências emergentes. Relatório Anual do Observatório Europeu das Drogas e da Toxicodependência. 2012;100-5.

91. Kronstrand R, Roman M, Thelander G, Eriksson A. Unintentional fatal intoxications with mitragynine and O-desmethyltramadol from the herbal blend Krypton. J Anal Toxicol. 2011;35:242-7.

92. Wise RA. Brain reward circuitry: insights from unsensed incentives. Neuron. 2002;36:229-40.

93. Cannon CM, Bseikri MR. Is dopamine required for natural reward? Physiol Behav. 2004;81:741-8. 


\section{Usos Lícito e llícito dos Fármacos}

Acta Med Port 2014:27:755-766

Publicado pela Acta Médica Portuguesa, a Revista Científica da Ordem dos Médicos

Av. Almirante Gago Coutinho, 151

1749-084 Lisboa, Portugal.

Tel: +351218428215

E-mail: submissao@actamedicaportuguesa.com

www.actamedicaportuguesa.com

ISSN:0870-399X | e-ISSN: 1646-0758

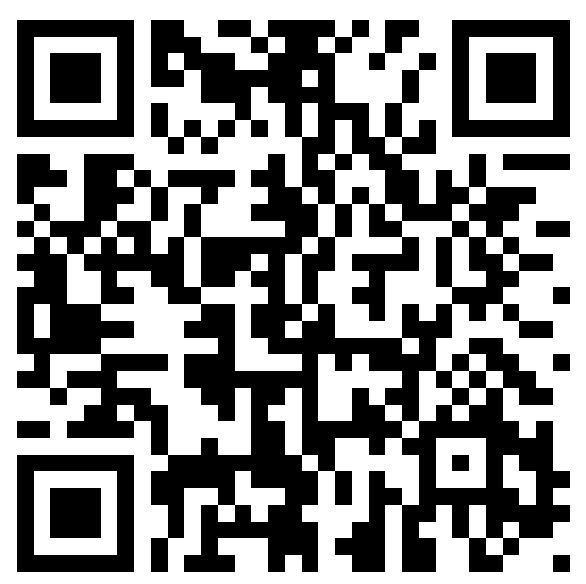

